\title{
Effects of physical exercise on butyrylcholinesterase in obese adolescents
}

\author{
Isabela M.W. Silva ${ }^{1}$, Neiva Leite ${ }^{2}$, Dellyana Boberg ${ }^{1}$, Thais J. Chaves ${ }^{1}$, Gerusa M. Eisfeld ${ }^{2}$, \\ Gisele M. Eisfeld ${ }^{2}$, Gleyse F. Bono ${ }^{1}$, Ricardo L.R. Souza ${ }^{1}$ and Lupe Furtado-Alle \\ ${ }^{1}$ Department of Genetics, Universidade Federal de Paraná, Curitiba, PR, Brazil. \\ ${ }^{2}$ Department of Physical Education, Universidade Federal de Paraná, Curitiba, PR, Brazil.
}

\begin{abstract}
The aim of the present study was to evaluate the effect of a 12 week program of physical exercise (PE) on butyrylcholinesterase (BChE) in obese adolescents. This study compared obese adolescents $(N=54)$ before and after $\mathrm{PE}$, regarding the relative intensity $(\mathrm{RI})$ and activity of different molecular forms (G1, G2, G4 and G1-ALB) of BChE found in plasma. Waist circumference (WC) and lipid profile were also assessed before and after PE. It was shown that before PE, mean plasma BChE activity was significantly higher in obese than in non-obese adolescents and that it was significantly reduced after PE, becoming similar to that found in non-obese adolescents. Lipid profile and WC also changed in response to PE. These results are consistent with studies that found a correlation between $\mathrm{BChE}$ and lipid metabolism and suggest that PE may have led to a physiological regularization of plasma BChE activity. Although mean BChE activity of each isoform was significantly reduced by PE, their RI did not change. This is in accordance with a previous suggestion that this proportion is maintained under factors such as obesity, and may therefore be important for BChE functions.
\end{abstract}

Key words: BChE activity; physical exercise, obesity.

Received: May 8, 2012; Accepted: July 20, 2012.

Butyrylcholinesterase (BChE; EC 3.1.1.8) is coded by $B C H E$ gene (3q26.1-q26.2), synthesized in the liver and distributed to several parts of the organism. Plasmatic $\mathrm{BChE}$ is found in four possible homomeric forms (G1 monomers, G2 dimmers, G3 trimers and G4 tetramers) or heteromeric forms formed in association with other proteins, such as albumin, G1-Alb (Masson, 1989).

Several studies verified that $\mathrm{BChE}$ has a role in lipid metabolism (Kutty et al., 1977), and is correlated with weight (Chautard-Freire-Maia et al., 1991; Li et al., 2008) and body mass index (Alcântara et al., 2001, 2003; Souza et al., 2005; Furtado-Alle et al., 2008). It is also known that plasma $\mathrm{BChE}$ activity is positively correlated with obesity (Kutty, 1980; Chautard-Freire-Maia et al., 1991; FurtadoAlle et al., 2008).

The aim of this study was to compare the relative intensity (RI) of $\mathrm{BChE}$ isoforms revealed as bands (G1, G1-Alb, G2 and G4) in obese adolescents before and after 12 weeks of physical exercise (PE), and to search for a correlation between RI of $\mathrm{BChE}$ isoform bands, plasma $\mathrm{BChE}$ activity and PE.

The sample comprised 54 obese adolescents (BMI above percentile 95 and mean age $12.6 \pm 2.01$ ), these being

Send correspondence to Lupe Furtado Alle. Departamento de Genética, Universidade Federal do Paraná, Caixa Postal 81531. 980, 19071 Curitiba, PR, Brazil. E-mail: lupealle@ gmail.com. participants of a 12 week program of physical exercise. Aerobic exercise consisted of 50 to 100 min activity during the first four weeks. Intensity was set at $35 \%-55 \%$ of $\mathrm{VO}_{2}$ peak, and was increased to $55 \%-75 \%$ during the next eight weeks. Plasma was sampled at baseline and after terminating the program. A sample of non-obese adolescents $(\mathrm{N}=45$; mean age $13.3 \pm 2.15)$ was used to measure plasma $\mathrm{BChE}$ activity.

The detection and analysis of $\mathrm{BChE}$ bands in plasma was made according to Boberg et al. (2010). Samples without any detectable $\mathrm{BChE}$ band were excluded from the analysis. Plasma BChE activity was measured according to Dietz et al. (1972), as modified by Evans and Wroe (1978). This study was approved by the Ethics Committee of Biological Sciences Sector from Federal University of Parana (05/2009).

Mean plasma $\mathrm{BChE}$ activity was significantly reduced after the 12 weeks program (before: $7.66 \pm 2.64$ $\mathrm{KU} / \mathrm{L}$, after: $5.89 \pm 2.34 \mathrm{KU} / \mathrm{L} ; \mathrm{t}=2.96, \mathrm{p}=0.008)$. Accompanying BChE activity, waist circumference (WC; before: $97.41 \pm 11.20 \mathrm{~cm}$, after: $94.62 \pm 10.51 \mathrm{~cm}, \mathrm{t}=3.6$ and $\mathrm{p}=0.03$ ), LDL-cholesterol (LDL-C; before: $94.45 \pm 20.83 \mathrm{mg} / \mathrm{dL}$, after: $86.00 \pm 16.37 \mathrm{mg} / \mathrm{dL}, \mathrm{t}=2.77$ and $\mathrm{p}=0.012$ ) and triglycerides (TG; before: $114.30 \pm 57.14 \mathrm{mg} / \mathrm{dL}$, after: $82.75 \pm 42.66 \mathrm{mg} / \mathrm{dL}, \mathrm{t}=3.1$ and $\mathrm{p}=0.006$ ) also showed significant reduction with $\mathrm{PE}$, 
Table 1 - Means $(M) \pm$ Standard Deviations (SD) of relative intensity (RI) and activity of BChE bands in obese adolescents $(\mathrm{n}=34)$ before and after a 12 week program of physical exercise.

\begin{tabular}{|c|c|c|c|c|c|c|c|}
\hline & \multicolumn{3}{|c|}{ Relative Intensity } & \multicolumn{4}{|c|}{ Activity (KU/L) } \\
\hline & \multicolumn{2}{|c|}{$\mathrm{M} \pm \mathrm{DP}$} & \multirow[t]{2}{*}{$t$-test (p) } & \multicolumn{2}{|c|}{$\mathrm{M} \pm \mathrm{DP}$} & \multirow[t]{2}{*}{$t$-test (p) } & \multirow[t]{2}{*}{ Means ratio $(\mathrm{B} / \mathrm{A})$} \\
\hline & Before & After & & Before & After & & \\
\hline G4 & $0.68 \pm 0.19$ & $0.72 \pm 0.19$ & $1.23(0.23)$ & $5.35 \pm 3.00$ & $4.29 \pm 2.29$ & $2.48(0.02)$ & 1.25 \\
\hline G2 & $0.13 \pm 0.09$ & $0.10 \pm 0.08$ & $1.51(0.14)$ & $0.99 \pm 0.65$ & $0.59 \pm 0.36$ & $3.19(0.003)$ & 1.68 \\
\hline G1-alb & $0.10 \pm 0.09$ & $0.10 \pm 0.09$ & $0.49(0.62)$ & $0.69 \pm 0.44$ & $0.42 \pm 0.43$ & $2.29(0.03)$ & 1.64 \\
\hline G1 & $0.09 \pm 0.08$ & $0.08 \pm 0.07$ & $0.23(0.82)$ & $0.77 \pm 0.64$ & $0.49 \pm 0.40$ & $2.52(0.02)$ & 1.57 \\
\hline
\end{tabular}

$\mathrm{B}=$ Before physical exercise, $\mathrm{A}=$ after physical exercise

while HDL cholesterol (HDL-C) showed a significant increase (before: $42.54 \pm 8.33 \mathrm{mg} / \mathrm{dL}$, after: $49.05 \pm 8.61 \mathrm{mg} / \mathrm{dL} ; \mathrm{t}=-4.53$ and $\mathrm{p}=0.0002)$. These changes in BChE activity, WC and lipid profile (LDL-C, TG and HDL-C) are consistent with an already described association between $\mathrm{BChE}$ and lipid metabolism. Considering that mean $\mathrm{BChE}$ activity in obese adolescents after the program was similar to that seen in non-obese adolescents $(5.0 \pm 0.11 \mathrm{KU} / \mathrm{L}, \mathrm{t}=1.5$ and $\mathrm{p}=0.13)$, and that mean $\mathrm{BChE}$ activity of each band was significantly reduced by PE (Table 1), the 12 weeks of PE may have led to a physiological regularization of plasmatic $\mathrm{BChE}$ activity. This contrasts with the lack of significance between means of RI of $\mathrm{BChE}$ isoform bands before and after the program (Table 1).

Boberg et al. (2010) had reported that higher plasma $\mathrm{BChE}$ activity is found in obese persons, the RI of each isoform is nonetheless maintained, independent of obesity. Our present data are in accordance with the observation made by Boberg et al. (2010), showing that, although mean $\mathrm{BChE}$ activity (total and related to each band, Table 1) decreased in response to PE, the RI of each band was maintained. This indicates that this proportionality is regulated and may therefore be important for $\mathrm{BChE}$ functions.

\section{Acknowledgments}

Grants and scholarships were received from Coordenação de Aperfeicoamento de Pessoal de Nivel Superior (CAPES) and Fundação Araucaria.

\section{References}

Alcântara VM, Rodrigues LC, Oliveira LC and Chautard-FreireMaia EA (2001) Association of the CHE2 locus with body mass index and butyrylcholinesterase activity. Hum Biol 73:587-595.
Alcântara VM, Oliveira LC, Réa RR, Suplicy HL and ChautardFreire-Maia EA (2003) Butyrylcholinesterase and obesity in individuals with the CHE2 C5+ and CHE2 C5- phenotypes. Int J Obes 27:1557-1564.

Boberg D, Furtado-Alle L, Souza RLR and Chautard-Freire-Maia EA (2010). Molecular forms of butyrylcholinesterase and obesity. Genet Mol Biol 33:452-454.

Chautard-Freire-Maia EA, Primo-Parmo SL, Picheth G, Lourenço MAC and Vieira MM (1991) The C5 isozyme of serum cholinesterase and adult weight. Hum Hered 41:330339.

Dietz AA, Rubinstein HM, Lubrano TE and Hodges LK (1972) Improved method for the differentiation of cholinesterase variants. Am J Hum Genet 24:58-64.

Evans RT and Wroe J (1978) Is serum cholinesterase activity a predictor of succinyl choline sensitivity? An assessment of four methods. Clin Chem 24:1762-1766.

Furtado-Alle L, Andrade FA, Nunes K, Mikami LR, Souza RLR and Chautard-Freire-Maia EA (2008) Association of variants of the -116 site of the butyrylcholinesterase $B C H E$ gene to enzyme activity and body mass index. Chem Biol Interact 175:115-118.

Kutty KM (1980) Biological function of cholinesterase. Clin Biochem 13:239-43.

Kutty KM, Redheendran R and Murphy D (1977) Serum cholinesterase: Function in lipoprotein metabolism. Experientia 33:420-421.

Li B, Duysen EG and Lockridge O (2008) The butyrylcholinesterase knockout mouse is obese on a high-fat diet. Chem Biol Interact 175:88-91.

Masson P (1989) A naturally occurring molecular form of human plasma cholinesterase is an albumin conjugate. Biochim Biophys Acta 988:258-266.

Souza RLR, Fadel-Picheth C, Allebrandt KV, Furtado L and Chautard-Freire-Maia EA (2005) Possible influence of $B C H E$ locus of butyrylcholinesterase on stature and body mass index. Am J Phys Anthropol 126:329-334.

Associate Editor: Mara Hutz

License information: This is an open-access article distributed under the terms of the Creative Commons Attribution License, which permits unrestricted use, distribution, and reproduction in any medium, provided the original work is properly cited. 